\title{
ADOLFO SÁNCHEZ VÁZQUEZ: SOBRE LA RELACIÓN ENTRE MARXISMO, DEMOCRACIA Y JUSTICIA
}

\section{ADOLFO SÁNCHEZ VÁZQUEZ ON THE RELATIONSHIP BETWEEN MARXISM, DEMOCRACY, AND JUSTICE}

\author{
Dr. Alberto Luis López ${ }^{1}$ \\ Western University/ Universidad Nacional Autónoma de México \\ Sistema Nacional de Investigadores (Conacyt)
}

Recibido: 3 septiembre 2019

Aceptado: 13 febrero 2020

\begin{abstract}
Resumen: En el presente artículo me aproximo a la relación que guarda el marxismo y la democracia con la idea de justicia que sostuvo el filósofo hispano-mexicano Adolfo Sánchez Vázquez. Para ello me serviré de algunas de sus principales obras pero sobre todo de sus escritos menores, porque en ellos se vislumbra de mejor manera la concepción de justicia del filósofo y se evidencia la estrecha relación de ésta con presupuestos marxistas y socialistas. Para llevar a cabo esta labor será también importante considerar su vida así como situarlo en su contexto, es decir, tener en cuenta desde su experiencia en la guerra civil española hasta su exilio y vida en el México de la segunda mitad del siglo XX.
\end{abstract}

Palabras clave: Sánchez Vázquez; marxismo; socialismo; democracia; justicia

\begin{abstract}
In this article I approach the issue of the relationship between marxism, democracy, and the idea of justice held by the Hispanic-Mexican philosopher Adolfo Sánchez Vázquez. For doing this, I will take into account some of his main works, but even more I will consider his minor works because they glimpse in a better way his conception of justice, and show the close relationship between such conception and the Marxist and socialist tenets. To do this it will be also important to consider both Sánchez Vázquez's life and his context, that is, take into consideration since his experience in the Spanish Civil war to his exile in Mexico in the second half of the 20th century.
\end{abstract}

Keywords: Sánchez Vázquez, Marxism, Socialism, Democracy, Justice

1. Miembro del Sistema Nacional de Investigadores nivel I. Postdoctor en Filosofía por la Universidad de Québec en Trois-Rivières, Canadá. Doctor en Filosofía por la UNAM. Maestro en Filosofía por la Universidad de Barcelona y Licenciado en Filosofía por la Universidad de Salamanca, España. alberto.luislopez@yahoo.com 
A mi padre, Alberto Luis Sánchez, cuya filiación marxista marcó mi vida. In memoriam.

\section{Introducción}

Adolfo Sánchez Vázquez escribió decenas de libros y cientos de artículos especializados y de opinión, que publicó tanto en revistas académicas como en medios de divulgación, sobre temas relacionados con el marxismo y la democracia; sin embargo, hasta donde tengo noticia no escribió un solo texto dedicado ex profeso al tema de la justicia. Esto puede deberse a que cuando arribó a México (1939) la filosofía que se desarrollaba en ese país giraba en torno, aunque no exclusivamente, al problema de la identidad del mexicano, siendo el Grupo Hiperión -influido por la obra de Samuel Ramos- el principal aglutinador de esas reflexiones. A partir de los años sesenta los cambios en las condiciones económicas, políticas y sociales de México derivaron en que las preocupaciones por la identidad dieran paso, tanto en el ámbito teórico-filosófico como en el social, a una etapa en la que se exigían mayores libertades y la democratización del Estado mexicano; pero no fue sino hasta finales del siglo XX cuando el tema de la justicia se convirtió en objeto de discusión y posteriormente en asunto de Estado ${ }^{2}$. Teniendo esto en cuenta y asumiendo que la consecución de la democracia, desde la perspectiva marxista de Sánchez Vázquez, era condición sine qua non para la llegada de la justicia, puede entenderse por qué nuestro autor no desarrolló un escrito, mucho menos una teoría elaborada, sobre la justicia y sí sobre la democracia y la libertad.

Es cierto que lo anterior puede dificultar nuestra labor de relacionar marxismo, democracia y justicia por no haber un escrito clave sobre este último tema, sin embargo, creo que es posible establecer esa relación si nos aproximamos a la idea de justicia del filósofo a partir, sobre todo, de sus escritos 'menores', es decir, de los artículos que publicó en periódicos, revistas y en volúmenes colectivos, pues es en ellos, más que en sus principales obras, en donde aparecen rastros, nociones e ideas sueltas que permiten bosquejar dicha idea. Además de esto, por la naturaleza del tema que nos ocupa será también importante acercarse a la vida del autor, porque muestra aspectos adicionales que sirven para bosquejar su idea de

2. Las tres etapas pueden delimitarse de la siguiente manera: 1) La publicación de $E l$ perfil del hombre y la cultura en México (1934) de Ramos abrió el camino a las reflexiones sobre la identidad. 2) A finales de los años cincuenta (1958-59) el movimiento ferrocarrilero representó un hito en la lucha por la democracia sindical, pero fue el movimiento estudiantil de 1968 el que exigió mayores libertades y la democratización del Estado mexicano. 3) La rebelión zapatista de 1994 puso en la mesa de la discusión nacional el tema de la justicia, pero no fue sino hasta 2018, con la llegada a la presidencia de López Obrador, que dicho tema se incorporó a la agenda del Estado mexicano.

Thémata. Revista de Filosofía №1 (2020) pp.: 65-83. 
justicia y relacionarla con los otros dos temas de nuestro escrito, de ahí que se haya dividido el presente artículo en tres apartados engarzados, a saber, 1) vida, 2) marxismo y 3) democracia socialista.

\section{Vida y circunstancias: el porqué de la defensa de la justicia}

La vida de Sánchez Vázquez (1915-2011) está llena de circunstancias que marcaron su inclinación por la justicia. Desde pequeño convivió con ideales de izquierda que en su caso devinieron socialistas, pues su padre, Benedicto Sánchez Calderón, fue un oficial del ejército español que desde 1931 defendió los principios republicanos y permaneció leal a la República durante y después de la sublevación militar del '36. Quizá por esta influencia republicana desde muy joven se sintió atraído por la política, pero como también le interesaba la literatura, en especial la poesía ${ }^{3}$, pronto adquirió una sensibilidad especial hacia el ser humano por tratarse de un ser básicamente creador. Por ello se decantó por las humanidades y se matriculó (1935) en la Facultad de Filosofía y Letras de la Universidad Central, donde destacaban figuras como Ortega y Gasset, Zubiri, García Morente y José Gaos. Él mismo narra esta decisión al reconocer que "una truncada práctica literaria y, más precisamente, poética, me llevó a problematizar cuestiones estéticas y una práctica política me condujo a la necesidad de esclarecerme cuestiones fundamentales de ella y, de esta manera, casi sin proponérmelo, me encontré en el terreno de la filosofía"4.

Al inicio de la guerra civil (18 de julio de 1936) Sánchez Vázquez militaba en las Juventudes Socialistas Unificadas ${ }^{5}$, por lo que decidió participar activamente en la guerra dirigiendo órganos de difusión y combatiendo al frente en el ejército republicano. Con el V Cuerpo pasó la última parte de la guerra en Cataluña, hasta que tras la batalla del Ebro se vio forzado a cruzar la frontera el 9 de febrero de $1939^{6}$. Estando en París se enteró del ofrecimiento de asilo del gobierno mexicano a los republicanos españoles y se acogió al mismo, por lo que el 13 de junio de 1939, desde el puerto francés de Sètes, abordó el buque "Sinaia" rumbo al puerto de Vera-

3. Él mismo rememora que incursionó en la poesía motivado por el poeta y editor Emilio Prados. Sánchez Vázquez, A.: "Vida y filosofía Postscriptum político-filosófico" en Del exilio en México o Recuerdos y reflexiones. México: Grijalbo, 1991, pp. 45-46.

4. Sánchez Vázquez, A.: "Mi obra filosófica" en Praxis y filosofía: ensayos en homenaje a Adolfo Sánchez Vázquez, González, J., Pereyra, C. y Vargas Lozano, G. (eds.). México, Grijalbo, 1985, p. 436.

5. Sánchez Vázquez, A.: "Recuerdos de la Guerra Civil en Málaga" en Revista de la Universidad de México 29, 2006, pp. 5-11.

6. Sánchez Vázquez, A.: "Vida y filosofía Postscriptum", cit., p. 56.

Thémata. Revista de Filosofía No61 (2020) pp.: 65-83. 
cruz en el Golfo de México. En esa época "México era un país desconocido" para él, aunque la expropiación petrolera (1938) y la idea de un gobierno revolucionario le hacían tener altas expectativas del lugar. Al llegar a suelo mexicano disfrutó de un buen recibimiento por parte de autoridades, obreros e intelectuales, lo que le permitió reactivar rápidamente su vida político-literaria ${ }^{8}$, la cual se vio enriquecida con su aprendizaje de una realidad social y política ajena a la suya pero que compartía elementos bien conocidos por él: pobreza, injusticia, desigualdad y falta de democracia.

Un evento importante fue su traslado a la ciudad de Morelia (1941) para dar clases de filosofía en el Colegio de San Nicolás de Hidalgo, institución con "tradición libertaria", porque allí vivió su primera experiencia mexicana de conflictos político-laborales que de alguna manera lo condujo a "entrar de lleno [...] en el terreno de la filosofía". Al regresar a la capital mexicana (1943) reanudó sus estudios universitarios en la carrera de Letras españolas, pero tras abandonarla temporalmente se percató de la importancia de fundamentar mejor su actividad política y decidió inscribirse en la Licenciatura en Filosofía.

Esos primeros años en México le hicieron repensar su formación académica pero también aprender de su condición de exiliado:

"El exiliado se ha quedado sin tierra [...] porque se vio forzado a abandonarla. Es sencillamente un desterrado. Y lo es porque su exilio no es un trans-tierro o el transplante de una tierra a otra, que vendría a ser simplemente la prolongación o el rescate de la que ha perdido. No es, por tanto, un trans-terrado. Ciertamente, el exiliado no se encuentra como en su tierra en la nueva que lo acoge. Esta sólo será su tierra, y lo será con el tiempo, no como un don con el que se encuentra a su llegada, sino en la medida en que comparte las esperanzas y sufrimientos de sus habitantes" ${ }^{10}$.

Destaco de la cita dos cosas, la primera es la distinción transterrado $\neq$ desterrado que evidencia el desacuerdo con la tesis del 'trans-tierro' de Gaos ${ }^{11}$, pues para Sánchez Vázquez no había trans-tierro, sino un

7. "México era un país desconocido que vagamente se asociaba a dos nombres tan contrapuestos como Hernán Cortés y Pancho Villa". Sánchez Vázquez, A.: "Recordando al Sinaia" en Del exilio en México, cit., p. 19.

8. A su llegada a México fundó las revistas Romance, España Peregrina y Ultramar, publicó el libro de poesías que había escrito en España, El Pulso ardiendo (1942), y reanudó su militancia activa en el Partido Comunista Español [PCE] sección mexicana.

9. Sánchez Vázquez, A.: "Vida y filosofía Postscriptum", cit., p. 64.

10. Sánchez Vázquez, A.: "Del exilio español en México" en Del exilio en México..., cit., p. 84.

11. Cfr. Ibidem, p. 62 y Sánchez Vázquez, A.: "De filósofos cercanos" (Joaquín Xirau) en Filosofía y circunstancias. Barcelona: Anthropos-Facultad de Filosofía y Letras, UNAM, 1997, p. 349. Recordemos que para Gaos el 'transterrado' era el que abandonaba su nación para establecerse en otra afín y en la que llegaba a sentirse identificado y "empatriado" (cfr. Gaos,

Thémata. Revista de Filosofía №1 (2020) pp.: 65-83. 
simple destierro. Éste consistía en un complejo proceso de adaptación a la nueva tierra ${ }^{12}$ porque el desterrado, al dejar su nación, vivía aferrado al pasado y dejaba de vivir el presente; por ello el exilio se convertía en "una herida que no cicatriza, una puerta que parece abrirse y nunca se abre"13. La segunda cuestión se relaciona con la idea de justicia porque el exiliado se arraiga a la nueva tierra en la medida en que comparte las 'esperanzas' y 'sufrimientos' del pueblo receptor. Hay que tener en cuenta que cuando habla de compartir ilusiones y angustias lo hace sobre todo en términos políticos, lo que significa que su asimilación a México se dio en la medida en que hizo suyas las esperanzas y sufrimientos del pueblo mexicano, y sin duda alguna ambas expectativas y sentimientos se relacionan con la justicia (social, económica, política y cultural), tanto con la esperanza de conquistarla como con el sufrimiento por no hacerlo.

Su arraigo a la nueva tierra se fortaleció al incorporarse a la UNAM como ayudante del profesor Eli de Gortari (1952), "un marxista de carne y hueso" ${ }^{14}$, quien lo apoyó en su tesis de maestría Conciencia y realidad en la obra de arte (1955). Esos años, determinantes para su formación filosófica, se compaginaron con su actividad política (representaba al PCE-mexicano en reuniones internacionales) y con su rechazo al autoritarismo de los comités centrales de la mayoría de los partidos comunistas de la época; esto lo llevó a adoptar una actitud teórica opuesta al discurso dominante del Diamat soviético y a intentar desarrollar un marxismo crítico a partir de dos principios del propio Marx: "dudar de todo" y "criticar todo lo existente" ${ }^{15}$. Aunado a esto, vivir en México le supuso vivir en un régimen político complejo y contradictorio (revolucionario, conservador y profundamente injusto) que le influyó para elaborar, tras ser nombrado profesor de tiempo completo (1959), su tesis doctoral Sobre la praxis (1967).

Asentado en México, fijó una postura crítica frente al dogmatismo teórico y los regímenes autoritarios y consolidó una concepción práctica de la filosofía, a la que concibió como una herramienta práctica que debía servir para alcanzar una relación "más justa -más humana [...] entre los hombres"16 y distinta con la naturaleza. La filosofía, así concebida, debía

Filosofía mexicana de nuestros días [1954] y Confesiones profesionales [1958]), mientras el 'desterrado' era simplemente aquél que al tener que dejar su patria pasaba a un lugar ajeno y distante.

12. Sánchez Vázquez, A.: "Del exilio español en México", cit., p. 92.

13. Sánchez Vázquez, A.: "Fin del exilio y exilio sin fin" en Ensayos marxistas sobre historia y política. México: Ediciones Océano, 1985, p. 165.

14. Cfr. Sánchez Vázquez, A.: "De filósofos cercanos” (Eli de Gortari), cit., p. 387.

15. Sánchez Vázquez, A.: "Vida y filosofía Postscriptum", cit., p. 71.

16. La razón amenazada, discurso del 22 de junio de 1984 al recibir el Doctorado honoris causas en la Universidad Autónoma de Puebla. Sánchez Vázquez, A.: "La razón amenazada"

Thémata. Revista de Filosofía No61 (2020) pp.: 65-83. 
enfrentar al quietismo y al 'irracionalismo teórico' que buscaba acabar con "todo intento -lucha o esfuerzo-por construir un mundo sin explotación ni dominación" ${ }^{17}$. Bajo esta concepción filosófica pasó su vida impartiendo cursos, dando conferencias y analizando desde la perspectiva marxista los grandes procesos sociales y políticos de la segunda mitad del siglo $\mathrm{XX}$, como fueron los golpes de Estado latinoamericanos (años 60 y 70), la muerte de Franco (1975), la desaparición del socialismo en la Europa del este (1991) o la caída del régimen priista (2000). Esos acontecimientos, en apariencia inconexos, le interesaron porque tenían como elemento común la lucha por la justicia, pues era ésta la que había llevado a esos pueblos, en sus diversas circunstancias, a luchar por sus derechos y por una vida más digna.

Sánchez Vázquez, en suma, se caracterizó por su compromiso político e intelectual en favor de la justicia y contra la explotación de las personas. Por eso su vida intelectual podría resumirse con las mismas palabras con las que definió la de Manuel Sacristán: puso su pensamiento "al servicio de la más noble causa que pueda abrazar un hombre de nuestro tiempo: la lucha contra la explotación y la opresión de todo tipo y, a su vez, por la construcción de una sociedad más justa y más racional en la que ya no puedan tener cabida [...] los explotadores y opresores de hombres y pueblos" ${ }^{18}$.

\section{Marxismo y Filosofía en la configuración del ideal de justicia}

El obligado exilio de Sánchez Vázquez por defender junto con otros la República española, es decir, "la libertad, la democracia y la soberanía asociadas a ella" 19 , resultó trágico pero también fecundo, porque lo obligó a pasar del ímpetu del luchador al estudio teórico para la transformación, es decir, tuvo que complementar su práctica socialista y su formación autodidacta con el estudio académico y riguroso del marxismo, lo que -como él mismo reconoció- le dio solidez y rigor a sus reivindicaciones sociales. Este proceso se dio de manera natural porque su interés por la filosofía fue simultáneo a su interés teórico por el marxismo, lo que propició que entre más conocía a la primera más se sintiera identificado con el segundo, al grado de asumir que filosofía y marxismo se fundían armónicamente.

Para nuestro autor, si el propio Marx como filósofo había retomado la tesis XI de Feuerbach con el propósito de pasar del análisis descriptivo a la transformación de las cosas, entonces aquellos interesados tanto en

en Filosofía y circunstancias, cit., p. 310.

17. Ibidem., p. 315.

18. Sánchez Vázquez, A.: "De filósofos cercanos" (Manuel Sacristán), cit., p. 351.

19. Ibidem, (Joaquín Xirau), cit., p. 347.

Thémata. Revista de Filosofía No61 (2020) pp.: 65-83. 
la filosofía como en cambiar las relaciones humanas encontraban en el marxismo la filosofía que fusionaba ambos intereses. Esta postura lo llevó a subrayar que la filosofía no sólo era una labor intelectual, sino que se trataba de una práctica que debía realizarse a través de la acción. En su discurso ¿Qué significa filosofar? (1993) ${ }^{20}$, aludió a esto al referirse a la distinción kantiana entre aprender filosofía y aprender a filosofar, la cual presuponía diferenciar entre el filosofar como actividad y la filosofía como resultado de dicho filosofar:

"Ciertamente, con su actividad propia, este sujeto u hombre concreto al que llamamos filósofo, produce esos objetos que son las doctrinas, teorías, categorías o conceptos filosóficos. Cualesquiera que sean sus frutos, cabe distinguir esa actividad por el modo de insertarse en la vida misma del filósofo, ya sea como una práctica especializada, profesional o académica, que se da sobre todo en los tiempos modernos (tal es el caso de un Kant, Hegel o Husserl), ya sea a extramuros de la academia o del aula, como sucede con el filosofar callejero de Sócrates, el práctico-político de Marx, o el mundano de Sartre" 21.

En esta cita aparecen tres elementos correlacionados (actividad, producto y práctica) importantes para nuestro autor, pues considera que la actividad del filósofo y los productos de ésta repercuten de diversa manera en su propia vida, de ahí que el filosofar derive en una práctica personal que revela la propia actividad del filósofo. Esta idea la ejemplifica consigo mismo al hablar sobre su propia actividad filosófica:

"Lo primero que quiero subrayar es la finalidad práctica, vital, a la que ha pretendido servir: transformar un mundo humano que, por injusto, no podemos ni debemos hacer nuestro. Sin desconocer la pesada carga de sospechas, desencantos y deformaciones que hoy tiene el calificativo 'marxista' de mi filosofar, lo sigo asumiendo para reafirmar mi adhesión al proyecto de emancipación que constituye la razón de ser del marxismo originario" 22 .

Para Sánchez Vázquez la actividad del filósofo debía manifestarse de manera práctica, por ello -en su caso-su actividad filosófica se expresó en su adhesión al marxismo como proyecto emancipador y en su rechazo al pensamiento dogmático (por eso su repudio al materialismo dialéctico soviético [Diamat] y al régimen stalinista [denunciado en el XX Congreso

20. Discurso pronunciado en 1993 en la UNED, España, para recibir el doctorado honoris causa.

21. Sánchez Vázquez, A.: “¿Qué significa filosofar?” en En torno a la obra de Adolfo Sánchez Vázquez (Filosofía, ética, estética y política). México: FFyL UNAM, 1995, p. 109.

22. Ibidem, p. 112.

Thémata. Revista de Filosofía No61 (2020) pp.: 65-83. 
del PCUS $\left.{ }^{23}\right]$ ), lo cual fue consecuencia de concebir al marxismo como un pensamiento que buscaba ser: i) una crítica a la sociedad capitalista, ii) un proyecto de emancipación individual y social, iii) una teoría que buscaba conocer la realidad y iv) una filosofía práctica ${ }^{24}$.

Su adhesión al marxismo, por tratarse de una filosofía teórica con actitud práctica, se explica mejor en su ensayo La filosofía de la praxis (balance personal y general) (1997), en donde afirma que tras sus estudios de la obra de Marx, en especial de los Manuscritos de París (1844), "La idea de Marx acerca del hombre como ser práctico, creador -aunque enajenado en la sociedad capitalista- junto con la idea del trabajo enajenado como negación de su actividad práctica, creadora, me condujeron a la idea del hombre como ser de la praxis y a la interpretación del marxismo como filosofía de la praxis" ${ }^{25}$.

A pesar de que se interesó desde joven por asuntos sociales y políticos, no fue sino hasta que estudió detenidamente a Marx que comprendió que el ser humano, como ser histórico-social y con actividad práctica ${ }^{26}$, es el que crea los valores y bienes que terminan por dominarlo, esto es, pese a ser aquéllos creaciones subjetivas (colectivas) se tornan objetivas y por eso les termina rindiendo culto: "el valor no lo poseen los objetos de por sí, sino que éstos lo adquieren gracias a su relación con el hombre como ser social"27. Este análisis, junto con el estudio de las Tesis sobre Feuerbach (1845) -como bien apunta Gandler ${ }^{28}$-, fue determinante para entender los conceptos de "enajenación" y "conciencia" (con los cuales detectó los mecanismos de los que se sirve el capitalismo para mantener un sistema social de explotación e injusticia) y para desarrollar su famosa obra Filosofía de la praxis (1967), en donde partiendo de caracterizaciones de la praxis hechas por filósofos de distintas épocas (desde la antigua Grecia,

23. En ese Congreso de 1956 el dirigente ruso Nikita Jrushchov leyó el llamado "Discurso secreto", en el que denunció los abusos del régimen totalitario stalinista.

24. Sánchez Vázquez, A.: "Marxismo y praxis" en A tiempo y destiempo. Antología de ensayos. México: FCE (ed. electrónica), 2013, pp. 269-274.

25. Sánchez Vázquez, A.: "La filosofía de la praxis (balance personal y general)" en Filosofía $y$ circunstancias, cit., p. 159.

26. Yurén, María Teresa: “Adolfo Sánchez Vázquez, una veta para la educación valoral” en Inventio 2, 3, 2006, pp. 61-70.

27. Sánchez Vázquez, A.: Ética, 20ª ed. México: Grijalbo, 1979, p. 118.

28. Cfr. Gandler, Stefan: "El pensamiento filosófico de Adolfo Sánchez Vázquez" en Revista de Hispanismo Filosófico 15, 2010. Gandler afirma que Sánchez Vázquez detectó en la obra de Marx los rasgos esenciales de una "verdadera" filosofía de la praxis, es decir, de una filosofía "de la transformación del mundo" (p. 12), e incluso se percató de la unidad entre el mundo material y su propia transformación, ya que el propio Marx situó en el centro de todas las relaciones humanas la actividad práctica del ser humano, que como tal resulta intrínsecamente "transformadora del mundo" (idem).

Thémata. Revista de Filosofía No61 (2020) pp.: 65-83. 
el Renacimiento y la Modernidad hasta Hegel, Feuerbach, Lenin y Marx), fundamentó su propio concepto de 'praxis' al entenderlo como "acción" y "práctica" humana conforme a fines: "la actividad humana [...] conforme a fines, y éstos sólo existen por el hombre, como productos de su conciencia. Toda acción verdaderamente humana exige cierta conciencia de un fin, el cual se supedita al curso de la actividad misma [...] al anticipar idealmente el resultado efectivo, puede ajustar sus actos como elementos de una totalidad regida por el fin" ${ }^{\prime 2}$.

Además de ser 'acción' y 'práctica', la categoría 'praxis' implicaba creación, imaginación y actividad libre y social, esto es, la praxis representaba la esencia de lo específicamente humano. Por esto mismo la praxis, asumida cabalmente, propiciaba también una nueva forma de hacer filosofía, dado que sumaba a su función epistémica una labor de corte crítico y político que le dotaba a la disciplina de mayores potencialidades. Esta nueva manera de hacer filosofía (práctica) compaginaba perfectamente con el marxismo, por tratarse -como señalamos- de un pensamiento práctico que buscaba conocer críticamente para emancipar. Por todo lo anterior, la 'praxis' fue un concepto central en el pensamiento de Sánchez Vázquez, porque a partir de él interpretó las distintas modalidades de la acción humana y al hacerlo se percató de los mecanismos enajenantes del sistema capitalista que sometían al individuo.

Esta relación intrínseca entre marxismo y justicia nos remite de nuevo al texto La filosofía de la praxis (balance personal y general), en donde se afirma:

"El marxismo se nos presenta, en primer lugar, como una crítica de lo existente por medio de la cual se expresa nuestra inconformidad con el mundo social que nos rodea. La crítica de esta realidad presente empuja a la búsqueda de una alternativa social en la que encuentren solución los males sociales que la crítica denuncia: o sea, la crítica remite a un proyecto de transformación de la realidad presente que se caracteriza, en relación con este presente injusto, como un proyecto de emancipación o liberación. Así pues, crítica y proyecto se hallan estrechamente enlazados"30.

El marxismo, por tanto, fue concebido por nuestro autor como una crítica convertida en teoría que buscaba eliminar la injusticia imperante, pero que -por su propia naturaleza- no se contentaba con teorizar la situación presente, sino que pretendía desencadenar una práctica e inspirar

29. Sánchez Vázquez, A.: Filosofía de la praxis. México: Siglo XXI, 2003, pp. 266-267. Recordemos que el concepto de 'trabajo', que definió como "fuente de todo valor, de toda riqueza" (Filosofía de la praxis, p. 142.), fue igualmente importante para su estudio sobre la 'praxis' y para la conformación de su filosofía.

30. Sánchez Vázquez, A.: "La filosofía de la praxis (balance personal y general)", cit., p. 162.

Thémata. Revista de Filosofía №1 (2020) pp.: 65-83. 
acciones conducentes al socialismo. Si el marxismo era una filosofía transformadora del mundo injusto, entonces los marxistas tenían que avivar "la crítica del capitalismo en cuanto sistema injusto que no puede resolver las contradicciones estructurales que generan sus injusticias" ${ }^{31}$, como la miseria, la destrucción de la naturaleza o la transformación del hombre en medio, instrumento o mercancía.

Un año después de este discurso pronunció otro titulado Por qué ser marxista hoy (2004) ${ }^{32}$, en el que argumentó que seguir siendo marxista obedecía a que se trataba de "una teoría crítica y una práctica encaminadas a transformar radicalmente el sistema económico-social en el que [algunos] ejercen su dominio y sus privilegios" ${ }^{33}$. Comprendía que la crisis por la caída del socialismo soviético hacía dudar si aún se podía ser marxista y si el marxismo todavía era viable. Como respuesta definió al marxismo como un conjunto de "ideas y valores" que constituían "un proyecto de transformación del mundo realmente existente, a partir de su crítica y de su interpretación o conocimiento. O sea, una teoría y una práctica en su unidad indisoluble" ${ }^{4}$, y arguyó que aún se podía ser marxista porque el socialismo de Marx no era otra cosa que una alternativa social al capitalismo, es decir, era una filosofía que buscaba transformar el mundo para eliminar la explotación de unos cuantos sobre la mayoría. Por consiguiente, ser marxista en el siglo XXI implicaba ser capaz de fundamentar tanto al marxismo como su viabilidad, esto es, ser capaz de contribuir teórica y prácticamente a la realización del mismo.

El marxismo, por tanto, era para Sánchez Vázquez una teoría plenamente vigente que luchaba por la justicia a la par que aspiraba a la verdad, pero para seguir siendo plausible debía cuestionar sus tesis fundamentales y contrastarlas con los hechos, en aras de confirmarlas, renovarlas o desecharlas. Incluso reconoció críticamente que "en la marcha para la necesaria transformación del mundo existente, hay que partir de Marx para desarrollar y enriquecer su teoría, aunque en el camino haya que dejar, a veces, al propio Marx" ${ }^{35}$. Esta actitud crítica le permitió analizar a detalle el marxismo y concluir que muchas de sus tesis eran vigentes porque la realidad las confirmaba. Por ejemplo, aún era válida la tesis de la naturaleza explotadora del capitalismo, los conceptos de clase (división

31. Ibidem, p. 164.

32. Discurso pronunciado en 2004 en la Universidad de La Habana para recibir el doctorado honoris causa.

33. Sánchez Vázquez, A.: "Por qué ser marxista hoy" en Ética y Política, México, FCE-FFyL UNAM, 2007, p. 112.

34. Ibidem, pp. 112-113.

35. Ibidem, p. 114.

Thémata. Revista de Filosofía ํ61 (2020) pp.: 65-83. 
social y lucha de clases), la expansión del capital, la mercantilización de toda forma de producción y la enajenación de todas las formas de relación humana; sin embargo, reconoció que había tesis que debían ajustarse, como la de las contradicciones de clase (pues había nuevas contradicciones como las étnicas, ambientales o de género), la que defendía una sola manera de acceder al poder, o la que interpretaba de manera dualista de la historia (o determinista [la historia la hacen los hombres en condiciones determinadas] o aperturista [todo depende de la conciencia, organización y acción humana]).

Finalmente, reconoció que había tesis obsoletas que debían abandonarse, como la relativa al sujeto de la historia (ya no podía sostenerse que la clase obrera fuese el único sujeto de cambio) o la del desarrollo ilimitado de las fuerzas productivas (era insostenible presuponer una producción ilimitada de bienes). Pese a esto, consideró que el marxismo aún era vigente por su carácter emancipador y porque constituía la única alternativa contra la explotación e injusticia connaturales al capitalismo.

\section{Democracia socialista: condición necesaria para la justicia}

Para hablar sobre la relación entre democracia (socialista) y justicia hay que tocar el tema del poder dentro del socialismo, pero para ello hay que referirse brevemente al pasado antidemocrático del mismo -porque cuando llegó al poder se volvió quasi dictatorial-y al tipo de justicia que propone ${ }^{36}$. Sobre este asunto, hay que recordar que Sánchez Vázquez le reconoció a Gramsci el mérito de haber sentado las bases para superar el dilema entre reforma o revolución y, en concordancia con el italiano, asumió que el acceso al poder debía ser resultado no sólo de la fuerza militar, sino también del consenso social, de la lucha política y de la reforma intelectual y moral ${ }^{37}$. No obstante, reconoció que la búsqueda del consenso no debía ignorar la naturaleza del poder político, al que entendía como violencia organizada, por lo que había que considerar que independientemente de la forma como se ejerciera el poder, es decir, con independencia del régimen, siempre existía una relación intrínseca entre éste y la violencia.

La diferencia entre el socialismo y el resto de sistemas políticos radicaba en cómo se entendía el poder. En el caso del socialismo, éste asumía como objetivo principal el paso del poder como dominación al poder como autodeterminación, lo que introducía la variable de la libertad y de la de-

36. Remito a la sugerente lectura de Sánchez Vázquez ("tercera tesis") sobre el uso del término "dictadura" en el marxismo. Cfr. Sánchez Vázquez, A.: "Once tesis sobre socialismo y democracia" en El valor del socialismo. México D.F.: Ítaca, 2000, pp. 113-116.

37. Sánchez Vázquez, A.: "La cuestión del poder en Marx. Sobre el poder" en Sistema 92, 1989, p. 12. Cfr. Yurén, María T.: “Adolfo Sánchez Vázquez, una veta...”, cit., p. 66.

Thémata. Revista de Filosofía No61 (2020) pp.: 65-83. 
mocracia, siendo la primera la capacidad de elección, decisión y acción e incorporando, a su vez, el tema de la responsabilidad. Es atendiendo a ésta que Sánchez Vázquez afirmaba, siguiendo a Marx, que los seres humanos hacen la historia bajo las condiciones que ellos determinan, pero también bajo las que los determinan a ellos ${ }^{38}$. Con esto quería decir que los seres humanos, como agentes históricos, tenían la responsabilidad de procurarse un sistema que reconociera su capacidad de elección y acción, esto es, de procurarse un sistema que garantizara la libertad (i.e., que fuese democrático) y que, por tanto, fuese condición de posibilidad para alcanzar la justicia y con ella la emancipación humana.

En relación con esto, para abolir la explotación y alcanzar la justicia no bastaba la democracia tradicional, es decir, la burguesa, hacía falta una verdadera democracia que sólo podía darse en el socialismo, pero no en el nominal como el soviético (por más que se autodefiniera como "real" o "desarrollado" 39 ), sino en el auténtico, esto es, el capaz de transitar del "deseo de justicia" (algo que también plantea la socialdemocracia) a la realización de la misma. Para este socialismo auténtico la democracia no era un simple proceso administrativo de elección, un componente utópico o una tendencia deseable, sino que se trataba de un elemento necesario y "efectivo" ${ }^{41}$; por eso Sánchez Vázquez sostuvo que bajo el verdadero socialismo no había cabida para "formas no democráticas", ya que "el carácter democrático del socialismo estriba en su naturaleza como sistema de autogestión social” ${ }^{42}$.

En consecuencia, la democracia socialista abogaba por la libertad porque era una democracia de y para la mayoría, pero para implementarla era necesario romper los límites que imponía la sociedad dominante burguesa (bajo el principio de la propiedad privada) al mantener al individuo replegado en sí mismo, en un individualismo radical que lo separaba de la comunidad. La verdadera democracia socialista constituía, pues, "un fin en sí o un valor intrínseco" 43 e implicaba la subordinación completa del Estado a la sociedad o, en otras palabras, la pérdida del carácter político

38. Véase, Sánchez Vázquez, A.: "Sobre el sujeto de la historia" en Filosofía y circunstancias, cit., pp. 246-253.

39. Sánchez Vázquez, A.: "Once tesis sobre socialismo", cit., p. 117. Sobre este punto la cuarta tesis sobre socialismo y democracia es clara: "En las sociedades del 'socialismo real' y, en particular, en la sociedad soviética como modelo de ellas, lo real es la ausencia de democracia, lo que impide caracterizarlas -dada la unidad indisoluble de socialismo y democracia- como socialistas". Cfr. Ibid., p. 116.

40. Sánchez Vázquez, A.: "Ideal socialista y socialismo real” en Ensayos marxistas, cit., p. 102.

41. Idem. Para nuestro autor una sociedad socialista tiene que ser democrática, pues "el concepto de socialismo incluye la forma democrática". Ibid., p 108.

42. Sánchez Vázquez, A.: “Once tesis sobre socialismo”, cit., p. 119.

43. Idem.

Thémata. Revista de Filosofía No61 (2020) pp.: 65-83. 
del Estado ${ }^{44}$. Esto conllevaba la desaparición de la burocracia como grupo social organizado jerárquicamente y convertido en "una nueva clase" 45 , "en una clase explotadora" 46 (como pasó en la URSS). Este grupo, al alejarse de la sociedad y ejercer el poder efectivo en nombre de la clase dominante, encarnaba lo que Marx llamó una "universalidad imaginaria" ${ }^{47}$ (por defender sus propios intereses). La desaparición de ese cuerpo parasitario llamado burocracia era, entre otras cosas, condición necesaria, no suficiente, para la democracia auténticamente socialista, pues sólo con ello se daría paso a la autogestión social y al control colectivo de las decisiones.

Para alcanzar esta democracia, condición sine qua non para la justicia, Sánchez Vázquez argumentaba que no era suficiente la democracia postulada por la clase dominante (fuese parlamentaria, electoral, formal o representativa), porque limitaba al sujeto participante a su "espacio propio", es decir, "a las casillas electorales en las que vota o el parlamento, a través de los representantes en los que ha delegado su voluntad" 48 , ni tampoco era suficiente la transformación de la estructura económica. Hacía falta una participación directa, constante y plena de los individuos en la toma de decisiones, por eso el valor de la verdadera democracia radicaba en que la participación consciente y racional en la toma de decisiones que afectaban a la comunidad respondía a una "exigencia de libertad" 49 y justicia. Por estas razones, la unión entre democracia y socialismo era indisoluble, porque éste sólo podía ser lo que se pretendía que fuera si iba de la mano con aquélla y porque sólo en el socialismo la democracia se podía ampliar, profundizar y realizar, al llevarla a todos los espacios de interacción (laboral, familiar o escolar) con el objetivo de favorecer la participación de los individuos en los asuntos que les afectaban.

La implementación plena de la democracia, no en la apariencia sino en los hechos, sólo era posible en un régimen realmente socialista, porque implicaba superar los límites que imponía el sistema social imperante. Es en este sentido que el filósofo afirmó que la auténtica democracia tenía un "potencial subversivo" ${ }^{50}$, pues no se trataba de una simple negación de la democracia formal, política o representativa, ni de elegir entre democracia representativa o directa. El verdadero objetivo era ejercer y enriquecer la

44. Sánchez Vázquez, A.: "Marx y la democracia” en Cuadernos políticos 36, 1983, p. 36.

45. Sánchez Vázquez, A.: "Ideal socialista y socialismo real” en Ensayos marxistas, cit., p. 109. Véanse ibidem, pp. 105-110.

46. Sánchez Vázquez, A.: "Once tesis sobre socialismo”, cit., p. 117.

47. Sánchez Vázquez, A., "Marx y la democracia", cit., p. 36.

48. Sánchez Vázquez, A.: "Democracia, revolución y socialismo" en Socialismo 3-4, 1989, p. 15.

49. Ibidem, p. 16.

50. Idem.

Thémata. Revista de Filosofía №1 (2020) pp.: 65-83. 
democracia en esas dos vertientes (representativa y directa) para avanzar hacia una "democracia real, económica y social", que fomentase e incluyese la participación de todos en todos los ámbitos, es decir, en los espacios en los que cada uno participaba y en las formas en las que lo hacía. Así, para el teórico de la praxis -acorde a sus Once tesis sobre socialismo y democracia- el auténtico socialismo iba unido a la auténtica democracia, dando como resultado una simbiosis que sentaba las bases para transitar del rechazo a las condiciones de explotación y de los deseos de algo mejor (aspiración socialdemócrata), a la "encarnación efectiva" de "las reivindicaciones de libertad, igualdad, justicia y democracia" ${ }^{51}$ (objetivo del socialismo).

Impulsar el socialismo y con ello la verdadera democracia implicaba entonces reconocer que ésta no podía limitarse a su forma política, sino que tenía que ampliarse a toda la vida social para alcanzar un nuevo tipo de convivencia, basado en una forma diferente de tomar las decisiones colectivas para hacerle frente a las prácticas de explotación, dominación y enajenación propias del capitalismo; por eso el filósofo de la praxis afirmó en su onceava tesis: "Los filósofos de la democracia se han limitado a interpretarla de diversas maneras, pero de lo que se trata es de conquistarla y ejercerla real, efectivamente" 52 .

\subsection{Apuntes sobre moral, política y justicia}

Para comprender mejor la relación simbiótica entre justicia y socialismo retomaremos el escrito Notas sobre la relación entre moral y política (1979), donde se aborda la estrecha relación entre moral y política y cómo ésta -añadiríamos- repercute en la consecución de la justicia. En ese escrito Sánchez Vázquez afirma que toda política supone cierta moral y toda moral una política. La moral la entiende como "peculiar regulación normativa de las relaciones entre los hombres", mientras la política la concibe como "actividad práctica social, como lucha de clases"53. Resulta evidente que moral y política tienen que ver directamente con las relaciones entre los individuos, lo que implica que ambas obedecen a intereses sociales y de clase. Esto pone de manifiesto que sumarse a un proyecto emancipatorio para transformar un mundo injusto es una opción política que conlleva una cuestión moral; por eso el revolucionario que busca transformar el mundo es un sujeto moral y por eso mismo, por ser revolucionario con exigencias morales, debe contribuir a la extinción de toda forma de dominación. Lo

51. Sánchez Vázquez, A.: "Después del derrumbe" en Entre la realidad y la utopía. Ensayos sobre política, moral y socialismo. México: FCE-FFyL UNAM, 2007, p. 245.

52. Sánchez Vázquez, A.: “Once tesis sobre socialismo”, cit., p. 120.

53. Sánchez Vázquez, A.: "Notas sobre la relación entre moral y política”, cit., p. 93.

Thémata. Revista de Filosofía $\mathrm{N}^{\circ} 61$ (2020) pp.: 65-83. 
anterior por dos motivos: 1) porque la "moral revolucionaria es la que [...] contribuye a la transformación del mundo" y 2) porque "es moral lo que sirve a la revolución, a la emancipación del hombre" ${ }^{54}$.

Este último punto no significa que la moral se convierta en sierva de la política, sino más bien que sirve a la política "ajustándose al interés de clase que coincide con esa emancipación" y "elevando y extendiendo socialmente el carácter consciente, libre y voluntario de la regulación nor-

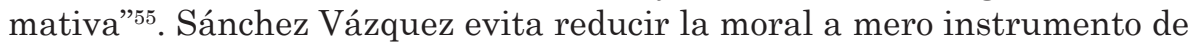
la política (revolucionaria) y por eso arguye que la "potenciación" de ésta debe conducir a la extinción del Estado, puesto que "el mejor Estado es aquél que prepara las condiciones para su propia extinción" ${ }^{\prime 6}$. Por tanto, dado que la mejor política es la que tiende a su propia negación, la política revolucionaria (socialista) ha de conducir tanto a la extinción del Estado, porque constituye una esfera de enajenación dado que su poder político (estatal) tiene un carácter particular y de $\operatorname{clase}^{57}$, como a la desaparición de la política misma, esto es, de esa lucha de clases por el poder que expresa la relación entre gobernantes y gobernados, o dirigentes y dirigidos.

Desde este punto de vista, para nuestro autor la moral no sólo no se reduce a instrumento de la política, sino que la política (revolucionaria) se subordina a la moral, porque su función es contribuir a que ésta se afirme frente al derecho y a la política misma, lo que significa que para lograr una transformación radical de la sociedad no es suficiente sustituir un poder (represivo) con otro; por el contrario, una vez instaurado un poder revolucionario éste -y eso es algo fundamental- debe crear las condiciones para su propia extinción. Sólo un poder como éste "abrirá el acceso a eso más allá [del poder como dominación] que consiste en la autodeterminación del individuo y la sociedad y, por tanto, a la verdadera realización de la libertad"58.

Se colige, por tanto, que en la búsqueda de una sociedad más justa y sin explotación la moral se convierte en una herramienta al servicio de la política revolucionaria (que pretende transformar esa sociedad), pero no se supedita a ella sino que se afirma ante ella, es decir, mantiene su propio ámbito, porque la lucha revolucionaria aspira a que el Estado mismo desaparezca y con él todas las formas políticas, históricas e institucionalizadas de coerción. Así, la auténtica moral sólo se construye en condiciones de libertad y ésta sólo se alcanza mediante la política revolucionaria de

54. Ibidem, p. 94.

55. Ibidem, p. 95.

56. Idem.

57. Sánchez Vázquez, A.: “La cuestión del poder en Marx...”, cit., pp. 4-11.

58. Sánchez Vázquez, A.: "El poder y la obediencia”, cit., p. 124.

Thémata. Revista de Filosofía No61 (2020) pp.: 65-83. 
corte socialista, pues sólo ella propicia "el carácter consciente, libre y responsable del individuo como agente moral"59. La justicia, por consiguiente, es consecuencia de esta relación entre moral y política, porque no hay socialismo sin una afirmación y potenciación real de la libertad pero la afirmación de ésta pasa, primero, por la afirmación de una política revolucionaria y, luego, por la negación de la política misma. Sólo así se alcanza la verdadera libertad que hace posible conquistar la justicia social.

\section{La justicia y su relación con el marxismo y la democracia: apuntes finales}

Para relacionar los tres temas de nuestro ensayo es necesario bosquejar la idea de justicia de Sánchez Vázquez, y para ello es importante tener en cuenta su vida, porque ayuda a entender que el filósofo andaluz no provino de una nación democrática, la guerra civil se originó en parte por el rechazo de la élite española a los nuevos modos democráticos, ni llegó a una nación que lo fuera, el México de los años treinta acababa de fundar el partido único de Estado (Partido de la Revolución Mexicana [1938] ${ }^{60}$ ), con la intención de gobernar y administrar la revolución. Por eso mismo, es decir, por haber vivido en países que distaban de ser democráticos, el filósofo de la praxis no redactó escritos sobre la justicia, pues en los años y países en que vivió la lucha social y política se enfocaba en conquistar la democracia y las libertades individuales, mismas que permitirían, como condición de posibilidad, la llegada de la justicia.

Pese a esto, podemos sintetizar lo planteado hasta ahora y esbozar la idea de justicia de nuestro autor, y para ello hay que comenzar diciendo que su estudio sobre el marxismo fue determinante en la configuración de su ideal de justicia. Gracias a éste comprendió que la historia humana ha consistido en una permanente lucha entre quienes se sirven de la mayoría para su propio beneficio y quienes reaccionan contra ello buscando una situación más equitativa. Cuando tuvo clara esta situación y cuando comprendió conceptos filosóficos como el de 'praxis', 'conciencia' y 'enajenación', fue que concibió la injusticia como la cancelación de las condiciones que hacen posible que un individuo se realice plenamente como humano. Esta cancelación se originaba cuando un conjunto de individuos, después convertidos en grupo o clase social, no sólo se aprovechaba de otros sino

59. Sánchez Vázquez, A.: "Notas sobre la relación entre moral y política", cit., p. 97.

60. Recordemos que el Partido de la Revolución Mexicana (PRM), fundado en 1938, procedía del Partido Nacional Revolucionario (PNR), fundado a su vez en 1929 por el general Plutarco Elías Calles con el objetivo de aglutinar a los grupos y partidos surgidos de la Revolución mexicana.

Thémata. Revista de Filosofía No61 (2020) pp.: 65-83. 
que creaba mecanismos, por lo general sutiles pero también evidentes, para dominarlos y con ello aprovecharse de los frutos de su trabajo. Los individuos despojados y como consecuencia explotados, se convertían en el producto o resultado de esa situación injusta, la cual -se percataran o no de ello- los llevaba a perder parte de su humanidad al dejar fuera de sí su capacidad de autorrealización.

Percatarse de esta situación, es decir, de la injusticia que se había ido consolidando a lo largo de la historia humana, es lo que llevó a nuestro autor a desarrollar una filosofía que tenía como propósito -como indica en su escrito La razón amenazada-impulsar una relación más justa y humana entre los hombres. Esta relación más justa nos lleva a sostener, a partir de lo dicho hasta aquí, que Sánchez Vázquez concebía a la justicia como el conjunto de condiciones económicas, sociales, políticas y culturales que organizadas racionalmente (no arbitraria ni intuitivamente) y apoyadas en un conocimiento de la realidad y de las fuerzas sociales ${ }^{61}$, establecían bases equitativas e igualitarias para todos, permitiendo con ello que cada uno tuviera las mismas posibilidades para desplegar el conjunto de sus capacidades; sin embargo, para el filósofo hispano-mexicano sólo en la democracia socialista de corte marxista era posible alcanzar esa relación equitativa e igualitaria (fruto de esas condiciones racionalmente estructuradas), porque era el único sistema que pretendía, como su razón de ser, establecer esa relación de facto y no sólo de iure, es decir, llevarla a la práctica y hacerla parte esencial de la vida cotidiana de las personas.

\section{Bibliografía}

Alonso, Ana J y Vicente Fernández González: "Adolfo Sánchez Vázquez y el exilio mexicano" en Transatlantic Studies Network: Revista de Estudios Internacionales 2, 3, 2017, pp. 91-94.

Álvarez, Federico (ed.): Adolfo Sánchez Vázquez. Los trabajos y los días. México: FFyL UNAM, 1995.

Gandler, Stefan: "El pensamiento filosófico de Adolfo Sánchez Vázquez" en Revista de Hispanismo Filosófico 15, 2010, pp. 9-29.

Gaos, José, Obras completas VIII. Filosofía mexicana de nuestros días. En torno a la filosofía mexicana. Sobre la filosofía y la cultura en México. México: UNAM, 1996.

González, J., Pereyra, C., Vargas Lozano G. (eds.): Praxis y filosofía, ensayos en homenaje a Adolfo Sánchez Vázquez. México: Grijalbo, 1985.

61. Sánchez Vázquez, A.: Ciencia y revolución: el marxismo de Althusser. México: Grijalbo, 1983, p. 115.

Thémata. Revista de Filosofía No61 (2020) pp.: 65-83. 
McCaughan, Edward J.: Reinventando la revolución. La renovación del discurso de la izquierda en Cuba y México. México: Siglo XXI editores, 1999, p. 85 ss.

Martínez, Francisco José: "Exilio y compromiso: el caso de Adolfo Sánchez Vázquez" en ARBOR Ciencia, Pensamiento y Cultura CLXXXV, 739, 2009, pp. 1009-1018.

Reyna, José L. y Trejo Delarbre, R.: La clase obrera en la historia de México: De Adolfo Ruiz Cortines a Adolfo López Mateos, 1952-1964. México: Siglo XXI - UNAM, 1981.

Sánchez Vázquez, A.: Ciencia y revolución: el marxismo de Althusser. México: Grijalbo, 1983.

: "Marx y la democracia" en Cuadernos políticos 36, 1983, pp. 31-39. : "Mi obra filosófica" en González, J., Pereyra, C., Vargas Lozano G. (eds.), Praxis y filosofía, ensayos en homenaje a Adolfo Sánchez Vázquez. México: Grijalbo, 1985.

: "Once tesis sobre socialismo y democracia" en El valor del socialismo. México D.F.: Ítaca, 2000.

: "Notas sobre la relación entre moral y política" en Ensayos marxistas sobre historia y política. México: Ediciones Océano, 1985 (publicado originalmente en Thesis. Nueva revista de Filosofía y Letras 5, 1980, pp. 17-19).

: "Ideal socialista y socialismo real", Ensayos marxistas sobre historia y política, México, Ediciones Océano, 1985 (publicado originalmente en 1979).

: "En torno al problema de la burocracia en Hegel y Marx", Investigación humanística 3 (otoño), 1987, pp. 15-26.

: "La cuestión del poder en Marx. Sobre el poder" en Sistema 92, 1989, pp. 3-18.

: "Democracia, revolución y socialismo" en Socialismo 3-4, 1989, pp.15-22.

: Del exilio en México o Recuerdos y reflexiones. México: Grijalbo, 1991.

: “Qué significa filosofar?” en En torno a la obra de Adolfo Sánchez Vázquez (Filosofía, ética, estética y política). México: Facultad de Filosofía y Letras, UNAM, 1995.

: "La razón amenazada" en Filosofía y circunstancias. Barcelona: Anthropos-Facultad de Filosofía y Letras, UNAM, 1997.

: El valor del socialismo. México D.F.: Ítaca, 2000.

: "Balance de la filosofía de la praxis" en Filosofía de la praxis. México:

Siglo XXI, 2003.

: Filosofía de la praxis. México: Siglo XXI, 2003.

: "Adolfo Sánchez Vázquez: Vida y filosofía. Páginas de memoria", en

Thémata. Revista de Filosofía No61 (2020) pp.: 65-83. 
La Gaceta del Fondo de cultura Económica 397, enero 2004, pp. 11-14. : Una trayectoria intelectual comprometida. México: UNAM, 2006. : "Recuerdos de la Guerra Civil en Málaga" en Revista de la Universidad de México 29, 2006, pp. 5-11.

: "Por qué ser marxista hoy" en Ética y Política. México: FCE- Facultad de Filosofía y Letras, UNAM, 2007.

: "Después del derrumbe" en Entre la realidad y la utopía. Ensayos sobre política, moral y socialismo. México: FCE-FFyL UNAM, 2007.

: "Marxismo y praxis" en A tiempo y destiempo. Antología de ensayos. México: FCE (ed. electrónica), 2013.

Simón, Paula: "El transterrado y el jardín: la experiencia del exilio en José Gaos y en José Donoso" en Revista de Literaturas Modernas 37, 2007, pp. 193-208.

Vargas Lozano, G. [en línea]: “Adolfo Sánchez Vázquez” en Enciclopedia Electrónica de la Filosofía Mexicana, http://dcsh.izt.uam.mx/cen_doc/ cefilibe/index.php/filosofos-mexicanos [consultado: 29/05/2019].

Yurén, María T.: "Adolfo Sánchez Vázquez, una veta para la educación valoral" en Inventio 3, 2006, pp. 61-70. 
